\title{
Dissolved organic sulfur in the ocean: Biogeochemistry of a petagram inventory
}

Kerstin B. Ksionzek, ${ }^{1,2 *}$ Oliver J. Lechtenfeld, ${ }^{1,7}$ S. Leigh McCallister ${ }^{3}$ Philippe Schmitt-Kopplin, ${ }^{4,5}$ Jana K. Geuer, ${ }^{1}$ Walter Geibert, ${ }^{1}$ Boris P. Koch $^{1,2,6 *}$

Although sulfur is an essential element for marine primary production and critical for climate processes, little is known about the oceanic pool of nonvolatile dissolved organic sulfur (DOS). We present a basin-scale distribution of solid-phase extractable DOS in the East Atlantic Ocean and the Atlantic sector of the Southern Ocean. Although molar DOS versus dissolved organic nitrogen (DON) ratios of $0.11 \pm 0.024$ in Atlantic surface water resembled phytoplankton stoichiometry (sulfur/nitrogen $\sim 0.08$ ), increasing dissolved organic carbon (DOC) versus DOS ratios and decreasing methionine-S yield demonstrated selective DOS removal and active involvement in marine biogeochemical cycles. Based on stoichiometric estimates, the minimum global inventory of marine DOS is 6.7 petagrams of sulfur, exceeding all other marine organic sulfur reservoirs by an order of magnitude.

n the early 1930s, Alfred Redfield noted that the ratio of carbon, nitrogen, and phosphorus in algal phyla remains surprisingly consistent across marine biomes. The canonical 106:16:1 Redfield ratio (1) originated from these observations and has since become a cornerstone of ocean biogeochemistry. Subsequent stoichiometric studies quantified the cellular quota of organic sulfur (OS) and found it to be similar to that of organic phosphorus $\left(\mathrm{C}_{124} \mathrm{~N}_{16} \mathrm{P}_{1} \mathrm{~S}_{1.3}\right)$ (2). The magnitude of $\mathrm{S}$ acquisition, assimilation, and metabolism is not trivial given an average molar elemental ratio of $\mathrm{C}_{124} \mathrm{~N}_{16} \mathrm{P}_{1} \mathrm{~S}_{1.3}$ for marine algae (2). Based on this $\mathrm{C} / \mathrm{S}$ ratio of $\sim 95$, the global phytoplankton biomass ( $1 \mathrm{Pg} \mathrm{C})(3)$ contains $0.028 \mathrm{Pg} \mathrm{S}$, and the annual net marine primary production (48.5 $\mathrm{Pg} \mathrm{C}$ year $^{-1}$ ) (4) requires a sulfur assimilation of $1.36 \mathrm{Pg} \mathrm{S}$ year $^{-1}$. Whereas regional marine dissolved organic sulfur (DOS) budgets have been constructed (5), quantification of the global inventory and its ties to other elemental biogeochemical cycles $(\mathrm{C}, \mathrm{N}$, $\mathrm{P}$, and $\mathrm{Fe}$ ) has been analytically hampered by the background concentration of sulfate $(29 \mathrm{mmol}$ $\mathrm{S} \mathrm{L}^{-1}$ ), which exceeds the concentration of DOS by five orders of magnitude.

The discovery of OS coupling to climate processes (6) generated a surge of interest in the OS cycle and dimethylsulfoniopropionate (DMSP) specifically. DMSP is the precursor of dimethylsulfide (DMS) (7), a gas that is assumed to contribute to aerosol formation and climate reg- ulation (6). The estimated annual production of DMSP by phytoplankton of $3.8 \mathrm{Pg} \mathrm{C} \mathrm{year}^{-1}$ or $2.0 \mathrm{Pg} \mathrm{S} \mathrm{year}^{-1}(8)$ represents an important sulfur assimilation pathway with rapid turnover rates and provides a substantial source of reduced carbon and sulfur for heterotrophic bacteria $(9,10)$. At the cellular level, the organic $\mathrm{S}$ and $\mathrm{N}$ cycles are intimately coupled through algal biosynthesis of the amino acids methionine and cysteine (11). Sulfur-rich peptides can also form metal-organic complexes and thus influence the speciation and mobility of trace metals in the ocean (12), with cascading effects on phytoplankton production, community composition, and carbon storage. Nonvolatile DOS is tightly linked to other major mineral assimilation pathways because it also comprises amino acids, vitamins, osmolytes, and primary metabolites $(13,14)$. The major sinks for these marine biogenic sulfur compounds are (i) remineralization to sulfate, (ii) incorporation into microbial biomass, (iii) efflux to the atmosphere (15), and (iv) transformation into the sizeable pool of nonvolatile marine dissolved organic matter (DOM) (662 Pg C) (16). Despite the relevance of marine DOS for ocean biogeochemistry, its quantitative depiction and

${ }^{1}$ Alfred Wegener Institute, Helmholtz Center for Polar and Marine Research, Am Handelshafen 12, 27570 Bremerhaven, Germany. ${ }^{2}$ MARUM Center for Marine Environmental

Sciences, Leobener Straße, D-28359 Bremen, Germany. ${ }^{3}$ Virginia Commonwealth University, Department of Biology, Center for Environmental Studies, 1000 West Cary Street, Richmond, VA 23284, USA. ${ }^{4}$ Helmholtz Zentrum München (HMGU), German Research Centre for Environmental Health, Institute for Ecological Chemistry, Analytical

BioGeoChemistry (BGC), Ingolstädter Landstraße 1, D-85764 Neuherberg, Germany. ${ }^{5}$ Technische Universität München, Chair of Analytical Food Chemistry, Alte Akademie 10, 85354 Freising, Germany. ${ }^{6}$ University of Applied Sciences, An der Karlstadt 8, 27568 Bremerhaven, Germany. ${ }^{7}$ UFZ-Helmholtz Centre for Environmental Research, Department of Analytical Chemistry, Permoserstraße 15, D-04318 Leipzig, Germany.

*Corresponding author. Email: kerstin.ksionzek@awi.de (K.B.K); boris.koch@awi.de (B.P.K.)
Fig. 1. Cruise track and distribution of DOS ${ }_{\mathrm{SPE}}$ and $D_{\text {DONE }}$ and molar DOC $\mathrm{SPE}_{\mathrm{SP}}$ / DOS $_{S P E}$ ratios in the surface ocean. (A) Surface DOS SPE concentrations ( $\mu \mathrm{mol} \mathrm{L}{ }^{-1}$ ) (colors) along the cruise track of research vessel Polarstern expeditions ANT XXV/1+2.

(B) $\mathrm{DOC}_{\mathrm{SPE}} / \mathrm{DOS}_{\mathrm{SPE}}$ ratios (contours) and DOS $\mathrm{SPE}_{\mathrm{SP}}$ concentrations $\left(\mu \mathrm{mol} \mathrm{L}{ }^{-1}\right)$ (colors). (C) Potential density anomaly $\sigma_{0}\left(\mathrm{~kg} \mathrm{~m}^{-3}\right)$ (contours) and DON $\mathrm{SPE}$ concentrations ( $\mu \mathrm{mol} \mathrm{L}{ }^{-1}$ ) (colors). For data below $200 \mathrm{~m}$ water depth, refer to Table 1.
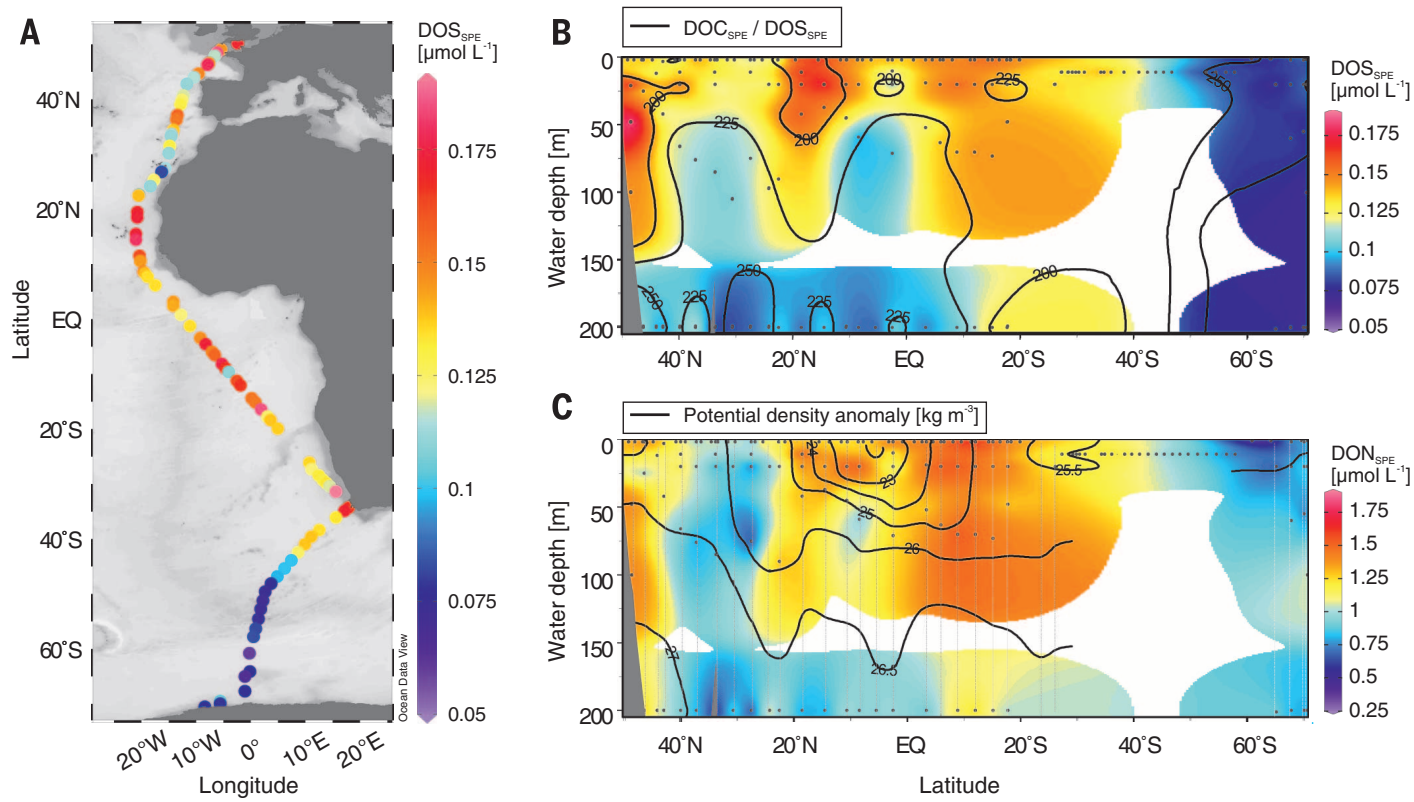
connections and feedbacks to the $\mathrm{C}$ and $\mathrm{N}$ cycle remain elusive.

This study is based on water samples from the East Atlantic (EA) and the Southern Ocean (SO) collected in November and December 2008 between $50.2^{\circ} \mathrm{N}$ and $70.5^{\circ} \mathrm{S}$ (Fig. 1A) (17, 18). The concentrations of solid-phase extractable DOS $\left(\right.$ DOS $_{\mathrm{SPE}}$ in $\mu \mathrm{mol} \mathrm{L} \mathrm{L}^{-1}$ seawater) were analyzed by inductively coupled plasma sector field mass spectrometry (ICP-MS). Similar to the ambient dissolved organic carbon (DOC) concentration $(17,18), \mathrm{DOS}_{\mathrm{SPE}}$ in the EA decreased significantly from $0.14 \pm$ $0.02 \mu \mathrm{mol} \mathrm{L}{ }^{-1}$ at surface depths of 0 to $105 \mathrm{~m}$ to $\leq 0.08 \pm 0.01 \mu \mathrm{mol} \mathrm{L} \mathrm{L}^{-1}$ in deeper water $\geq 200 \mathrm{~m}(P<0.001)$ (Fig. 1B and Table 1). DOS SPE $_{\text {cor- }}$ related linearly with both extractable dissolved organic nitrogen $\left(\mathrm{DON}_{\mathrm{SPE}}\right)$ and $\mathrm{DOC}_{\mathrm{SPE}}(P<0.001$, $\left.R_{\mathrm{DOC}}=0.86, R_{\mathrm{DON}}=0.75\right)(\mathrm{Fig}$. $1 \mathrm{C}$ and fig. S1A), whereas the slopes differed significantly $(P<0.001)$. The molar $\mathrm{DOS}_{\mathrm{SPE}} / \mathrm{DON}_{\mathrm{SPE}}$ ratios of $0.11 \pm 0.024$ were almost constant (slope of 5.3) throughout the water column and comparable to phytoplankton stoichiometry (S/N $0.08, \mathrm{C}: \mathrm{N}: \mathrm{S}=124: 16: 1.3)(2)$, suggesting a predominantly biogenic DOS imprint (19) rather than abiotic incorporation of $\mathrm{S}$ into DOM as found in oxygen-limiting conditions (20). In contrast, molar $\mathrm{DOC}_{\mathrm{SPE}} / \mathrm{DOS}_{\mathrm{SPE}}$ ratios in the EA increased with depth from $213 \pm 25$ in the surface to $268 \pm$ 39 in deeper water (slope of 99.7; $P<0.001$ ), suggesting higher biological reactivity of DOS relative to DOC. This is supported by earlier studies showing that microbial growth can be limited by the availability of reduced sulfur sources such as DMSP $(9,10)$.

$\mathrm{DOS}_{\mathrm{SPE}}$ concentrations in the SO were pervasively low, whereas primary production was relatively high (see fig. S2 for chlorophyll concentrations). Depth-related changes in $\mathrm{DOS}_{\mathrm{SPE}}$ concentrations of $0.08 \pm 0.01 \mu \mathrm{mol} \mathrm{L}{ }^{-1}$ in the surface and $0.07 \pm 0.01 \mu \mathrm{mol} \mathrm{L} \mathrm{L}^{-1}$ at $\geq 200 \mathrm{~m}$ depth and changes in molar $\mathrm{DOC}_{\mathrm{SPE}} / \mathrm{DOS}_{\mathrm{SPE}}$ ratios of $262 \pm 28$ in the surface and $254 \pm 26$ at $\geq 200 \mathrm{~m}$ were insignificant $(P>0.05)$ (Table 1 ). Molar $\mathrm{DOS}_{\mathrm{SPE}} / \mathrm{DON}_{\mathrm{SPE}}$ ratios of $0.10 \pm 0.027$ were similar to those found in the EA. A correlation of chlorophyll $a$ with DOC or DOS was not observed. We speculate that the biogenic signature of DOS production was not detected due to short residence times in the mixed surface water and upwelling of old (5226 \pm 64 years), nonlabile DOS from the deep SO (16) with low $\operatorname{DOS}_{\mathrm{SPE}}$ concentrations $\left(0.07 \pm 0.001 \mu \mathrm{mol} \mathrm{S} \mathrm{L}^{-1}\right)$ (Table 1).

To provide an estimate of nonlabile DOS removal, we correlated measured and reconstructed $\mathrm{DOC}_{\mathrm{SPE}}$ radiocarbon ages $(17,18)$ with $\mathrm{DOS}_{\mathrm{SPE}}$ concentrations (fig. S1B). Based on first-order kinetics, we found a strong correlation ( $R=$ $0.75, P<0.01)$ of $\mathrm{DOS}_{\mathrm{SPE}}$ concentration with age, similar to that previously determined for $\operatorname{DOC}_{\mathrm{SPE}}(17,18)(R=0.61, P<0.01)$. The longterm degradation rate coefficients for $\mathrm{DOS}_{\mathrm{SPE}}$ of $k_{\mathrm{DOS}}=2.54 \times 10^{-4}$ year $^{-1}$ and $\mathrm{DOC}_{\mathrm{SPE}}$ of $k_{\mathrm{DOC}}=$ $1.53 \times 10^{-4}$ year $^{-1}$ differed significantly $(P<0.001)$ and reflected a higher reactivity (lability) of $\mathrm{DOS}_{\mathrm{SPE}}$ compared with $\mathrm{DOC}_{\mathrm{SPE}}$. The long-term net removal rate of $2.7 \times 10^{-5} \mu \mathrm{mol} \mathrm{S} \mathrm{L}{ }^{-1}$ year $^{-1}$ for this nonlabile $\operatorname{DOS}_{\mathrm{SPE}}$ pool (see the supplementary materials for definition) results in stoichiometric changes in DOM over time and depth, similar to the preferential remineralization of $\mathrm{N}$ (and $\mathrm{P}$ ) relative to $\mathrm{C}(21)$. In contrast, degradation rate coefficients for $\mathrm{DOS}_{\mathrm{SPE}}$ and $\mathrm{DON}_{\mathrm{SPE}}$ were similar and, consequently, molar $\mathrm{DOS}_{\mathrm{SPE}} / \mathrm{DON}_{\mathrm{SPE}}$ ratios did not change significantly with age. Differences between $\mathrm{DOS}_{\mathrm{SPE}}$ and $\mathrm{DOC}_{\mathrm{SPE}}$ degradation kinetics are also reflected in $\mathrm{DOS}_{\mathrm{SPE}}$ and $\mathrm{DOC}_{\mathrm{SPE}}$ lifetimes (time at which the DOM concentration decreases to $1 / e$ of its initial value): We calculated the average lifetime of DOS $\mathrm{SPE}_{\mathrm{SE}}$ of $\tau=3937$ years, which is lower than the lifetime for DOC of $\tau=$ 4500 years (18) and $\mathrm{DOC}_{\mathrm{SPE}}$ of $\tau=6536$ years (see the supplementary materials for details). As the molecular composition of the DOC and DOS pools differs, a direct comparison of $\mathrm{DOS}_{\mathrm{SPE}}$ degradation kinetics with commonly applied DOC fractions (labile, semilabile, or refractory), which are based on the DOC removal rate and lifetime (22), cannot be applied. Our results also indicate that DOS degradation kinetics, similar to previous studies on DOC (17), are determined by a continuum of reactivities of the contributing sulfur compounds rather than discrete degradation stages.

Relative changes in the contribution of labile DOS derived from biogenic production to the total DOS pool were assessed from two depth profiles analyzed for total hydrolysable methionine-sulfur yield [i.e., mole \% of methionine-S versus total $\left.\mathrm{DOS}_{\mathrm{SPE}}\right]$. In the EA, we found a higher molar methionine-sulfur yield of $1.02 \pm 0.14 \%$ in the surface water compared with $0.21 \pm 0.10 \%$ in deeper water $(\geq 200 \mathrm{~m})$. Accordingly, we observed a considerable decrease of the methionine-sulfur yield with age (fig. S3). In the SO, the methionine-sulfur yield of $0.18 \pm$ $0.04 \%$ was consistently low throughout the water column. Assuming a methionine-S:cysteine-S ratio of 1.7 (11), less than $2 \mathrm{~mol} \%$ of the $\mathrm{DOS}_{\mathrm{SPE}}$ was protein-derived. This low value is consistent with previous data on amino acid carbon yield (23) suggesting that labile DOS in the form of sulfur-containing amino acids is efficiently remineralized or transformed, even in the surface ocean.

For the molecular characterization of DOS, we used Fourier transform ion cyclotron resonance mass spectrometry (FT-ICR-MS) and identified 803 unique molecular formulas containing predominantly one sulfur atom, 81 of which were exclusively identified in surface water $\leq 105 \mathrm{~m}$ (total number of $\mathrm{S}$ formulas in the data set, 81,037). None of the formulas we detected occurred uniquely at depth or matched the composition of a peptide. However, it is likely that other sulfur-containing compounds were also present and not covered by our analytical window. The diversity of sulfurcontaining compounds identified by FT-ICR-MS and the average molecular $\mathrm{S} / \mathrm{C}$ ratio in the $\mathrm{EA}$ decreased significantly from $0.06 \pm 0.001$ in surface water to $0.05 \pm 0.001$ in deeper water ( $\geq 200 \mathrm{~m} ; P<0.001$ ) (Fig. 2), whereas comparable trends in the SO were not observed. Similar to previous molecular studies on $\operatorname{DOC}(17,18)$, the most persistent $\mathrm{S}$ formulas at depth showed higher unsaturation (lower molecular hydrogen/carbon ratio) (Fig. 2) and slightly larger molecular size $(427 \pm 5.6 \mathrm{Da}$ in surface water and $441 \pm 10.9 \mathrm{Da}$ at $\geq 200 \mathrm{~m}$ ).

The SPE method applied (24) yields lower extraction efficiencies for highly polar organic compounds (e.g., $22 \%$ for marine DON) as compared with DOC (42\%) $(17,18)$. Changes of the DOC and DON extraction efficiencies with depth, however, were insignificant $\left(P_{\mathrm{DOC}}=0.85, P_{\mathrm{DON}}=\right.$ 0.45). Therefore, we can assume that the extraction yield for polar OS compounds is also lower than for DOC and independent of water depth. Using the average measured molar $\mathrm{DOC}_{\mathrm{SPE}} /$ $\mathrm{DOS}_{\mathrm{SPE}}$ ratio (Table 1) and the DOC concentrations in original seawater, we can reconstruct 


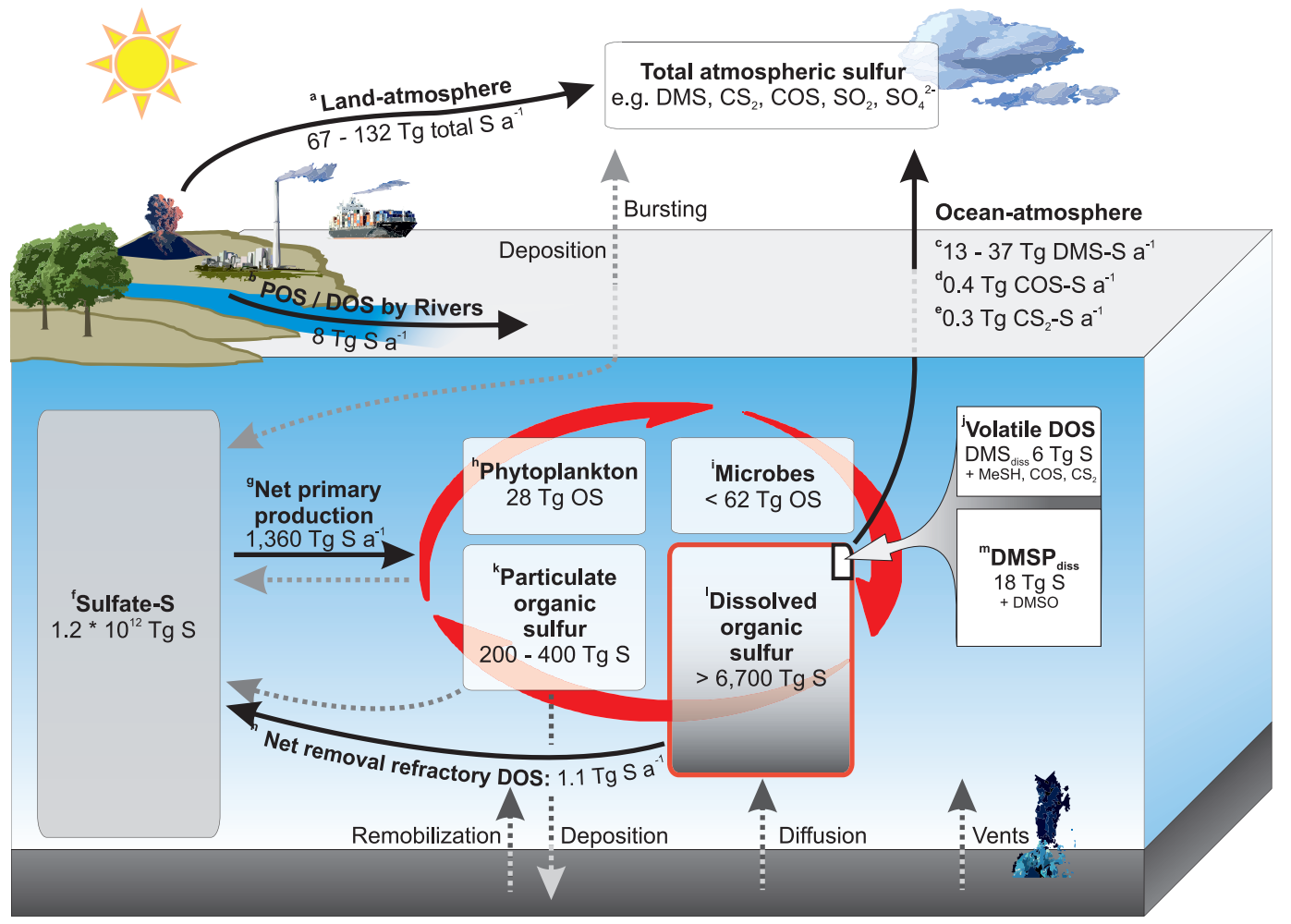

Fig. 3. Simplified marine organic sulfur cycle. Schematic overview of organic sulfur reservoirs and fluxes. All numbers refer to organic sulfur, except for the oceanic sulfate inventory and the land-atmosphere flux (total S). Known and calculated organic sulfur fluxes are shown as solid lines and unknown fluxes as dotted lines. The red circle indicates the rapid and important cycling of labile DOS compounds such as DMSP (depicted in the small white box). For corresponding data and references, see table S3.

Table 1. Average values and root mean square deviations of $\mathrm{DOC}$ and sulfur concentrations in

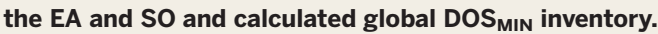

\begin{tabular}{|c|c|c|c|c|c|}
\hline & \multicolumn{5}{|c|}{ Depth intervals } \\
\hline & 0-105 m & $200 \mathrm{~m}$ & 201-1000 m & $>1000 \mathrm{~m}$ & Total* \\
\hline \multicolumn{6}{|l|}{ East Atlantic Ocean } \\
\hline$n^{\dagger}$ & $106(108)$ & 21 & 5 & $11(8)$ & $143(142)$ \\
\hline DOC $\left(\mu \mathrm{mol} \mathrm{L}^{-1}\right)$ & $71 \pm 12$ & $54 \pm 4$ & $49 \pm 5$ & $46 \pm 2$ & $47 \pm 3$ \\
\hline $\mathrm{DOC}_{\mathrm{SPE}}\left(\mu \mathrm{mol} \mathrm{L}^{-1}\right)$ & $29 \pm 5$ & $23 \pm 3$ & $20 \pm 1$ & $20 \pm 1$ & $21 \pm 1$ \\
\hline $\mathrm{DOS}_{\mathrm{SPE}}\left(\mu \mathrm{mol} \mathrm{L}^{-1}\right)$ & $0.14 \pm 0.02$ & $0.10 \pm 0.02$ & $0.09 \pm 0.03$ & $0.07 \pm 0.01$ & $0.08 \pm 0.01$ \\
\hline DOC & $213 \pm 25$ & $235 \pm 30$ & $241 \pm 47$ & $276 \pm 38$ & $268 \pm 39$ \\
\hline$[\mathrm{DOS}]_{\mathrm{MIN}}\left(\mu \mathrm{mol} \mathrm{L}^{-1}\right)$ & $0.34 \pm 0.08$ & $0.23 \pm 0.04$ & $0.21 \pm 0.05$ & $0.16 \pm 0.03$ & $0.18 \pm 0.03$ \\
\hline \multicolumn{6}{|l|}{ Southern Ocean } \\
\hline$n^{+}$ & $22(21)$ & $3(2)$ & 3 & 3 & $31(29)$ \\
\hline DOC $(\mu \mathrm{mol} \mathrm{L}-1)$ & $50 \pm 11$ & 48 & $48 \pm 6$ & $49 \pm 6$ & $49 \pm 7$ \\
\hline $\mathrm{DOC}_{\mathrm{SPE}}\left(\mu \mathrm{mol} \mathrm{L}^{-1}\right)$ & $21 \pm 2$ & $21 \pm 1$ & $21 \pm 0.3$ & $18 \pm 4$ & $19 \pm 3$ \\
\hline $\mathrm{DOS}_{\mathrm{SPE}}\left(\mu \mathrm{mol} \mathrm{L}^{-1}\right)$ & $0.08 \pm 0.01$ & $0.07 \pm 0.003$ & $0.07 \pm 0.005$ & $0.07 \pm 0.001$ & $0.07 \pm 0.01$ \\
\hline$D_{S O C_{S E}} / D O S_{S P E}$ & $262 \pm 28$ & $288 \pm 17$ & $294 \pm 14$ & $246 \pm 29$ & $255 \pm 26$ \\
\hline$[\mathrm{DOS}]_{\mathrm{MIN}}\left(\mu \mathrm{mol} \mathrm{L}^{-1}\right)$ & $0.19 \pm 0.04$ & 0.16 & $0.16 \pm 0.02$ & $0.20 \pm 0.01$ & $0.19 \pm 0.01$ \\
\hline \multicolumn{6}{|l|}{ Total average } \\
\hline$n^{\dagger}$ & $128(129)$ & $24(23)$ & 8 & $14(11)$ & $174(171)$ \\
\hline $\mathrm{DOC}\left(\mu \mathrm{mol} \mathrm{L}^{-1}\right)$ & $68 \pm 14$ & $53 \pm 4$ & $49 \pm 5$ & $47 \pm 4$ & $48 \pm 5$ \\
\hline $\mathrm{DOC}_{\mathrm{SPE}}\left(\mu \mathrm{mol} \mathrm{L}^{-1}\right)$ & $28 \pm 5$ & $23 \pm 3$ & $21 \pm 1$ & $20 \pm 2$ & $20 \pm 2$ \\
\hline $\mathrm{DOS}_{\mathrm{SPE}}\left(\mu \mathrm{mol} \mathrm{L}^{-1}\right)$ & $0.13 \pm 0.03$ & $0.10 \pm 0.02$ & $0.08 \pm 0.02$ & $0.07 \pm 0.01$ & $0.08 \pm 0.01$ \\
\hline $\mathrm{DOC}_{\mathrm{SPE}} / \mathrm{DOS} \mathrm{SPE}_{\mathrm{SP}}$ & $221 \pm 31$ & $241 \pm 34$ & $261 \pm 46$ & $270 \pm 38$ & $266 \pm 39$ \\
\hline$[\mathrm{DOS}]_{\mathrm{MIN}}\left(\mu \mathrm{mol} \mathrm{L}^{-1}\right)$ & $0.31 \pm 0.09$ & $0.23 \pm 0.04$ & $0.19 \pm 0.05$ & $0.17 \pm 0.03$ & $0.18 \pm 0.03$ \\
\hline \multicolumn{6}{|l|}{ Global } \\
\hline $\mathrm{DOC}(\mathrm{Pg})^{13}$ & & 7 & 138 & 477 & 662 \\
\hline $\mathrm{DOS}_{\text {MIN }}(\mathrm{Pg})$ & & 6 & 1.4 & 4.7 & 6.7 \\
\hline
\end{tabular}

*Depth-integrated values. ${ }^{\dagger}$ Number of samples for the DOS SPE analysis. Numbers in parentheses are the numbers of samples for DOC analysis. a conservative minimum for the original DOS concentration in seawater ([DOS $]_{\mathrm{MIN}}$ ) (Table 1 and Eq. 1).

$[\mathrm{DOS}]_{\mathrm{MIN}}=[\mathrm{DOC}] /\left(\mathrm{DOC}_{\mathrm{SPE}} / \mathrm{DOS}_{\mathrm{SPE}}\right)$

where [DOC] is the molar DOC concentration in original seawater and $\mathrm{DOC}_{\mathrm{SPE}} / \mathrm{DOS}_{\mathrm{SPE}}$ is the measured molar elemental ratio in the extracts. The calculated $[\mathrm{DOS}]_{\mathrm{MIN}}$ concentrations were $0.34 \pm 0.08$ and $0.19 \pm 0.04 \mu \mathrm{mol} \mathrm{L}^{-1}$ in EA and SO surface waters, respectively (Table 1 ). This concentration range was consistent with previous data from the Sargasso Sea (0.04 to $0.4 \mu \mathrm{mol}$ DOS L $\left.{ }^{-1}\right)(5)$. For comparison, the mean concentrations of dissolved DMS and DMSP in the surface of the EA during our cruise were 0.0036 and $0.0032 \mu \mathrm{mol} \mathrm{L} \mathrm{L}^{-1}$, respectively (25), representing $\sim 2 \%$ of $[\mathrm{DOS}]_{\mathrm{MIN}}$ in the EA. The global average concentration for dissolved DMS and DMSP were previously estimated at 0.001 to $0.007 \mu \mathrm{mol} \mathrm{L}^{-1}$ (26) and $0.003 \mu \mathrm{mol} \mathrm{L}^{-1}(27)$, respectively, contributing only $\sim 2.3 \%$ of the total $[\mathrm{DOS}]_{\mathrm{MIN}}$.

Based on the global oceanic DOC inventory of $662 \mathrm{Pg} \mathrm{C}(16)$ and depth-integrated molar $\mathrm{DOC}_{\mathrm{SPE}} / \mathrm{DOS}_{\mathrm{SPE}}$ ratios, the minimum global oceanic DOS inventory ( DOS $_{\mathrm{MIN}}$ ) is $6.7 \mathrm{Pg} \mathrm{S}$ (6700 Tg), $\sim 600 \mathrm{Tg}$ of which are present in the upper $200 \mathrm{~m}$ of the water column (Table 1 and Fig. 3). If we assume that the molar $\mathrm{C} / \mathrm{S}$ ratio of $\sim 95$ in phytoplankton is the lowest possible ratio for DOM, the maximum size of the global DOS inventory is $18.6 \mathrm{Pg} \mathrm{S}$. Hence, DOS represents the major reservoir of organic $S$ in the ocean, larger than OS in biomass, particles, or 
volatile compounds combined (Fig. 3). More important, these numbers raise new questions on the marine sulfur budgets: Only 13 to $37 \mathrm{Tg} \mathrm{S}$ year $^{-1}$ of the total DOS pool (red frame in Fig. 3) are released to the atmosphere as DMS (28) and DOS degradation products such as carbonyl sulfide (COS) $\left(0.4 \mathrm{Tg} \mathrm{S}_{\text {year }}{ }^{-1}\right)$ and carbon disulfide $\left(\mathrm{CS}_{2}\right)\left(0.3 \mathrm{Tg} \mathrm{S}\right.$ year $\left.^{-1}\right)$ (Fig. 3) (28). In total, these fluxes represent less than $3 \%$ of the annual sulfur assimilation of $1.36 \mathrm{Pg} \mathrm{S}$ year ${ }^{-1}$ by primary production, suggesting that rapid biogeochemical cycles of labile sulfur compounds (red cycle in Fig. 3) are superimposed on the large background of nonlabile DOS (red frame in Fig. 3), which we consider to be derived from the microbial carbon pump (29). Seasonal variation of $\mathrm{C} / \mathrm{S}$ ratios by changes in production and microbial or photodegradation has an important effect on the DOS $_{\text {MIN }}$ estimates in the surface (5). However, the value for our global DOS $_{\mathrm{MIN}}$ estimate is dominated by the relatively invariant $\mathrm{C} / \mathrm{S}$ ratios of $266 \pm 41$ in the large water body below the photic zone $(>200 \mathrm{~m})$ and therefore only marginally affected by seasonal effects. Many previous studies focused on the labile (and partly volatile) proportion of the DOS cycle (Fig. 3). This study enables important insights into the biogeochemistry of the vast pool of nonlabile DOS. So far, the organic sulfur budgets cannot be closed, particularly because the connection between the rapid cycling of labile DOS and the nonlabile proportion of the organic sulfur cycle remain unquantified.

\section{REFERENCES AND NOTES}

1. A. C. Redfield, B. H. Ketchum, F. A. Richards, in The Sea, M. N. Hill, Ed. (Wiley, New York, 1963), vol. 2, chap. 2.

2. T. Y. Ho et al., J. Phycol. 39, 1145-1159 (2003).

3. P. G. Falkowski, R. T. Barber, V. Smetacek, Science 281, 200-206 (1998).

4. C. B. Field, M. J. Behrenfeld, J. T. Randerson, P. Falkowski, Science 281, 237-240 (1998).

5. G. A. Cutter, L. S. Cutter, K. C. Filippino, Limnol. Oceanogr. 49, 555-565 (2004).

6. R. J. Charlson, J. E. Lovelock, M. O. Andreae, S. G. Warren, Nature 326, 655-661 (1987).

7. M. O. Andreae, Mar. Chem. 30, 1-29 (1990).

8. M. Galí, E. Devred, M. Levasseur, S.-J. Royer, M. Babin, Remote Sens. Environ. 171, 171-184 (2015)

9. H. J. Tripp et al., Nature 452, 741-744 (2008).

10. R. P. Kiene, L. J. Linn, J. González, M. A. Moran, J. A. Bruton, Appl. Environ. Microbiol. 65, 4549-4558 (1999)

11. J. Giovanelli, S. H. Mudd, A. H. Datko, J. Biol. Chem. 253 , 5665-5677 (1978).

12. D. S. Smith, R. A. Bell, J. R. Kramer, Comp. Biochem. Physiol. C 133, 65-74 (2002).

13. M. A. Moran et al., Proc. Natl. Acad. Sci. U.S.A. 113, 3143-3151 (2016).

14. B. P. Durham et al., Proc. Natl. Acad. Sci. U.S.A. 112, 453-457 (2015).

15. P. Schmitt-Kopplin et al., Biogeosciences 9, 1571-1582 (2012)

16. D. A. Hansell, C. A. Carlson, D. J. Repeta, R. Schlitzer Oceanography 22, 202-211 (2009).

17. R. Flerus et al., Biogeosciences 9, 1935-1955 (2012)

18. O. J. Lechtenfeld et al., Geochim. Cosmochim. Acta 126, 321-337 (2014)

19. M. Gonsior et al., Mar. Chem. 123, 99-110 (2011)

20. R. L. Sleighter et al., Environ. Sci. Technol. Lett. 1, 345-350 (2014).

21. C. S. Hopkinson Jr., J. J. Vallino, A. Nolin, Deep Sea Res. Part II Top. Stud. Oceanogr. 49, 4461-4478 (2002)

22. D. A. Hansell, Ann. Rev. Mar. Sci. 5, 421-445 (2013)

23. J. Davis, R. Benner, Limnol. Oceanogr. 52, 2434-2444 (2007)

24. T. Dittmar, B. P. Koch, N. Hertkorn, G. Kattner, Limnol. Oceanogr. Methods 6, 230-235 (2008).

25. C. Zindler, C. A. Marandino, H. W. Bange, F. Schutte, E. S. Saltzman, Geophys. Res. Lett. 41, 3181-3188 (2014).
26. A. Lana et al., Global Biogeochem. Cycles 25, 17 (2011).

27. R. P. Kiene, D. Slezak, Limnol. Oceanogr. Methods 4, 80-95 (2006).

28. D. C. Yoch, Appl. Environ. Microbiol. 68, 5804-5815 (2002). 29. N. Jiao et al., Nat. Rev. Microbiol. 8, 593-599 (2010).

\section{ACKNOWLEDGMENTS}

This work was supported by the DFG-Research Centre/Cluster of Excellence "The Ocean in the Earth System" and a Ph.D. grant by the Deutsche Forschungsgemeinschaft (DFG) in the framework of the priority program "Antarctic Research with comparative investigations in Arctic ice areas" (grant KO 2164/ 8-1+2). We are grateful to research vessel Polarstern captain, crew, and chief scientists G. Kattner (ANTXXV-1) and O. Böbel (ANTXXV-2); I. Stimac is acknowledged for technical support with ICP-MS analysis and K.-U. Ludwichowski for support with methionine analysis; we thank C. Marandino for DMS and DMSP data; S. Frickenhaus is acknowledged for support with statistical analysis, and B. Kanavati, M. Harir, and J. Uhl for support with FT-ICR-MS analyses. G. Kattner and R. Alheit are acknowledged for helpful discussions and proofreading. The data presented in this paper are available at the PANGEA data library (doi:10.1594/ PANGAEA.858568). B.P.K. designed the research. O.J.L and B.P.K. collected and processed the samples. K.B.K. and W.G. performed ICP-MS analysis and data evaluation. J.G. carried out methionine analyses, S.L.M. performed ${ }^{14} \mathrm{C}$ analysis, and P.S.-K. performed FT-ICR-MS analysis. The paper was written by K.B.K. and B.P.K, with input from all coauthors.

\section{SUPPLEMENTARY MATERIALS}

www.sciencemag.org/content/354/6311/456/suppl/DC1 Materials and Methods

Figs. S1 to S3

Tables S1 to S3

References (30-36)

30 March 2016; accepted 15 September 2016

Published online 6 October 2016

10.1126/science.aaf7796

\section{A disynaptic feedback network activated by experience promotes the integration of new granule cells}

\section{Diego D. Alvarez, ${ }^{*}$ Damiana Giacomini, ${ }^{*}$ Sung Min Yang, Mariela F. Trinchero, Silvio G. Temprana, Karina A. Büttner, Natalia Beltramone, Alejandro F. Schinder $†$}

Experience shapes the development and connectivity of adult-born granule cells (GCs) through mechanisms that are poorly understood. We examined the remodeling of dentate gyrus microcircuits in mice in an enriched environment (EE). Short exposure to EE during early development of new GCs accelerated their functional integration. This effect was mimicked by in vivo chemogenetic activation of a limited population of mature GCs. Slice recordings showed that mature GCs recruit parvalbumin $\gamma$-aminobutyric acidreleasing interneurons (PV-INs) that feed back onto developing GCs. Accordingly, chemogenetic stimulation of PV-INs or direct depolarization of developing GCs accelerated GC integration, whereas inactivation of PV-INs prevented the effects of EE. Our results reveal a mechanism for dynamic remodeling in which experience activates dentate networks that "prime" young GCs through a disynaptic feedback loop mediated by PV-INs.

N

eural stem cells (NSCs) of the adult hippocampus follow a multifaceted developmental program that culminates in the generation of dentate granule cells (GCs) capable of information processing (1-4). The pathway from NSC to GC offers multiple checkpoints that are controlled by physiological and pathological conditions, which ultimately modulate the efficacy and quality of the neurogenic process (5-9). Thus, simple experiences such as physical exercise or exploration of novel environments can influence the production, maturation, survival, and connectivity of adult-born GCs

Laboratorio de Plasticidad Neuronal, Fundación Instituto Leloir-Instituto de Investigaciones Bioquímicas de Buenos Aires-Consejo Nacional de Investigaciones Científicas y Técnicas (CONICET), Av. Patricias Argentinas 435, Buenos Aires C1405BWE, Argentina.

*These authors contributed equally to this work. †Corresponding author. Email: aschinder@leloir.org.ar
(10-14). Yet the early transition from NSC to neuron is much better understood than the processes that control the subsequent steps resulting in the functional integration of new neurons into the preexisting network. We investigated how experience is translated into local signals that can shape the developmental profile of new GCs.

Adult-born GCs were studied during their initial 3 weeks in the temporal hippocampus, where development occurs at a slow pace and is sensitive to behavior $(12,15,16)$. We first asked whether an experience that activates the dentate gyrus might work as a signal to shape neuronal development. Because spatial exploration actively involves hippocampal processing (17-19), an enriched environment (EE) was selected as a stimulus to promote hippocampal activity. A brief exposure to EE reliably activated a substantial fraction of principal cells in the GC layer (fig. S1). We subsequently tested 


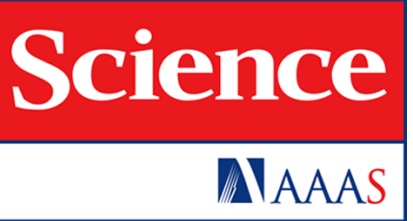

Editor's Summary

\section{Dissolved organic sulfur in the ocean: Biogeochemistry of a} petagram inventory

Kerstin B. Ksionzek, Oliver J. Lechtenfeld, S. Leigh McCallister, Philippe Schmitt-Kopplin, Jana K. Geuer, Walter Geibert and Boris P. Koch (October 6, 2016)

Science 354 (6311), 456-459. [doi: 10.1126/science.aaf7796]

originally published online October 6, 2016

\section{Inventory of an essential marine element}

Sulfur is necessary for marine primary production and has a large impact on climate processes. Because it is difficult to detect accurately, the amount of dissolved organic sulfur in the ocean is poorly defined. Ksionzek et al. measured dissolved organic sulfur in the Atlantic to estimate its distribution and infer its quantity in the world's oceans (see the Perspective by Levine). The findings suggest that dissolved organic sulfur exceeds all other forms of organic sulfur by a factor of 10 .

Science, this issue p. 456; see also p. 418

This copy is for your personal, non-commercial use only.

Article Tools Visit the online version of this article to access the personalization and article tools:

http://science.sciencemag.org/content/354/6311/456

Permissions Obtain information about reproducing this article:

http://www.sciencemag.org/about/permissions.dtl

Science (print ISSN 0036-8075; online ISSN 1095-9203) is published weekly, except the last week in December, by the American Association for the Advancement of Science, 1200 New York Avenue NW, Washington, DC 20005. Copyright 2016 by the American Association for the Advancement of Science; all rights reserved. The title Science is a registered trademark of AAAS. 